\title{
Improving Quality of Crystalline Glucose as Priority for Development of Its Technology
}

\author{
Khvorova L. S., Lukin N.D. \\ The All-Russian Research Institute of Starch Products - FGBNU branch "Federal scientific center of food systems by V.M. \\ Gorbatov" of RAS, \\ Moscow Region, Lyuberetsky District, Kraskovo \\ email: vniik@arrisp.ru
}

\begin{abstract}
Crystal glucose is one of the main products of starch production, pharmaceutical and food industries, veterinary medicine. Great demands are placed on the quality of crystal glucose to minimize impurities and improve microbial purity. The article discusses the sources and causes of impurities in crystals, based on studies of the content of colored impurities in glucose crystals and their migration throughout the volume of the crystal, as well as measures to reduce and eliminate them. The presence of impurities was determined by the color intensity of the crystal solutions when measuring their optical density. It was found that the optical density of solutions is higher for crystals of large fractions. At the same time, crystals of fine fraction have up to $44 \%$ of coloring impurities on their surface and $56 \%$ - in the volume of crystals; in crystals of the coarse fraction is the ratio of the impurities is $30 \%$ and $70 \%$, respectively. The main sources of accumulation of impurities in the crystals are admixtures of starch, the conditions of conversion of starch and catalysts, types of adsorbents, as well as the technological regimes of crystallization, especially during the start of crystals. The use of enzymes for the hydrolysis of starch, activated carbons and ion exchange resins that meet the requirements of glucose production contributes to the reduction of color and improve the quality of crystals. The use of activated carbon of GN-A3 brand (Germany) has shown high efficiency in the discoloration and purification from mineral elements. The use of active coal for discoloration in combination with ion exchange resins can improve the technological and technical and economic indicators in the production of glucose. The use of technology for the production of glucose in anhydrous form, surfactants for seed crystals at the stage of crystal nucleation, reduces the number of seeds, improves the quality of glucose, by reducing the content of impurities and increasing microbial purity.
\end{abstract}

Keywords-Glucose, impurities in crystals, sources of impurity, perfecting of technology

\section{INTRODUCTION}

Crystal glucose is one of the main products of starchtreacle production, medical and food industry [1]. In the pharmaceutical industry, glucose is used for the preparation of infusion solutions, as a filler in the tableting of drugs and an independent food product in dietary and sports nutrition [2], as a raw material for the production of sorbitol [3], ascorbic acid [4], as well as for the preparation of solutions in veterinary [5]. Due to the lack of domestic production, crystal glucose in Russia is purchased abroad. Infusion solutions are also purchased on import. The need for solutions is more than 350 million conventional packages (bottles of $450 \mathrm{ml}$ ) per year [6]. About half of this amount of solutions is produced by domestic pharmaceutical companies from imported glucose, the rest are purchased abroad. Advanced modern technologies of glucose production should provide high quality for use in the food and pharmaceutical industry [7]. Crystal glucose is obtained from corn or wheat starch

With the help of acid and enzymes, the starch suspension is hydrolyzed with the breakdown of the starch molecule to glucose. The resulting solutions are filtered, purified with adsorbents, concentrated by evaporation of water under vacuum, then followed by the stage of crystallization of glucose, separation of crystals from the mother solution on centrifuges and drying them.

\section{MATERIALS AND METHODS}

Research to improve the technology of each stage is aimed at accelerating the processes and improving the quality of crystalline glucose.

\section{A. Objects of researches, methods and devices}

Crystal glucose, developed by acid and enzyme saccharification of starch, import glucose, glucose syrups received by enzyme conversion of starch were the objects of researches.

\section{B. Devices and methods of research}

The carbohydrate composition of the solution was determined by the carbohydrate analyzer (UHH) of the company "BISHOFF", protein by the method of Kjeldahl apparatus B-324 of BUCHI firms; fat Soxhlet method; determination of granulometric composition of crystals was performed using a Leica DMLM microscope MBI-4; specific rotation was measured with polarimeter Polartronic NH8 made by "Schmidt + HAENSCH"; the optical density of solutions was measured on the spectrophotometer SF-44; ash content was determined by burning glucose in a muffle furnace.

\section{RESULTS OF RESEARCHES}

Results of researches of crystal food glucose by protein content, ash and fat are presented in table 1 . 
TABLE I. RESULTS OF THE ANALYSIS OF CRYSTAL GLUCOSE

\begin{tabular}{|c|l|l|l|}
\hline \multirow{2}{*}{ Sam } & \multicolumn{3}{|c|}{ Contents, \% by dry solids (DS) } \\
\cline { 2 - 4 } & Fat & Protei & Ash \\
\hline 1 & 0.039 & 0.062 & 0.048 \\
\hline 2 & 0.065 & 0.034 & 0.058 \\
\hline 3 & 0.040 & 0.040 & 0.057 \\
\hline 4 & 0.051 & 0.045 & 0.044 \\
\hline 5 & 0.038 & 0.051 & 0.046 \\
\hline Japa & 0.055 & 0.024 & 0.059 \\
\hline Yug & 0.066 & 0.053 & 0.064 \\
\hline
\end{tabular}

It is seen from the table that all samples of domestic and import glucose contained fat $-0.038-0.066 \%$, protein $-0.024-$ $0.062 \%$, ash particles $-0.044-0.064$. At the same time it is difficult to reveal dependence on technology and technique.

The samples from Yugoslavia received by continuous crystallization have the impurity content which is the same as the samples of domestic glucose. The Japanese sample of glucose received by the most perfect technology also contains a particular, though the least, amount of protein and fat

Researches on definition of impurity migration from syrup to crystals and their distributions throughout the crystal volume basis are conducted.

\section{A. Study on distribution of impurity in glucose crystals}

The studies were aimed at determining the level of impurities and their volume distribution. As a starting material for the study two samples of food-grade crystalline glucose were taken, obtained by the acid method as the most informative in the number and composition of impurities. Both samples were divided in series into 3 fractions (table. 2).

TABLE II. DISTRIBUTION OF GLUCOSE CRYSTALS SIZES

\begin{tabular}{|c|c|c|c|c|}
\hline \multirow{2}{*}{$\begin{array}{c}\text { Name of } \\
\text { samples }\end{array}$} & \multirow{2}{*}{$\begin{array}{c}\text { Mass of } \\
\text { glucose, }\end{array}$} & \multicolumn{3}{|c|}{ Distribution of crystals sizes by sizes, } \\
\cline { 3 - 5 } & & $>0.25 \mathrm{~mm}$ & $\begin{array}{c}0.25- \\
0.11 \mathrm{~mm}\end{array}$ & $<0.11 \mathrm{~mm}$ \\
\hline glucose1 & 495 & 83.9 & 179.0 & 232.1 \\
\hline glucose 2 & 539 & 77.8 & 200.5 & 260.7 \\
\hline
\end{tabular}

For the three fractions we obtained the following results in $\%$ : small - 47-48, average - 36-37, large - 14.5-16.5.

In an average sample of two glucose samples, the optical density of solutions in fractions of large and small crystals was determined (Tab. 3) and distribution of coloring substances on the volume of crystals. It follows from the table that the optical density of the solutions increases with the size of the crystals.

There are data on determination of content and distribution of colorants on the volume basis of a crystal. When carrying out experiments, a shot of $20 \mathrm{~g}$ of glucose crystals was sequentially affined, 5-6 times with a saturated solution of pharmaceutical glucose, and then affined crystals were subjected to serial fractional dissolution (5-6 times) with an unsaturated solution of the same pharmaceutical glucose. The selected samples of solutions both initial and received as a result of affination and dissolutions of crystals were analyzed by indexes of dry solids (DS) and an optical density.

TABLE III. INDEXES OF AN OPTICAL DENSITY OF CRYSTALS SOLUTIONS FOR DIFFERENT SIZE FRACTIONS

\begin{tabular}{|c|c|c|c|}
\hline \multirow{2}{*}{$\begin{array}{c}\text { Lengths of } \\
\text { waves, nm. }\end{array}$} & \multicolumn{3}{|c|}{ Optical density of solutions, nm (Sample 1) } \\
\cline { 2 - 4 } & $>0.25 \mathrm{~mm}$ & $0.25-0.11 \mathrm{~mm}$ & $<0.11 \mathrm{~mm}$ \\
\hline 220 & 0.78 & 0.72 & 0.70 \\
\hline 260 & 0.52 & 0.43 & 0.42 \\
\hline 280 & 0.59 & 0.48 & 0.48 \\
\hline
\end{tabular}

In fig. 1a, b, there are curves of an optical density of solutions with various ranges $(220-720 \mathrm{~nm})$ of a spectrophotometer SF-44 for fractions of small and large crystals of glucose.

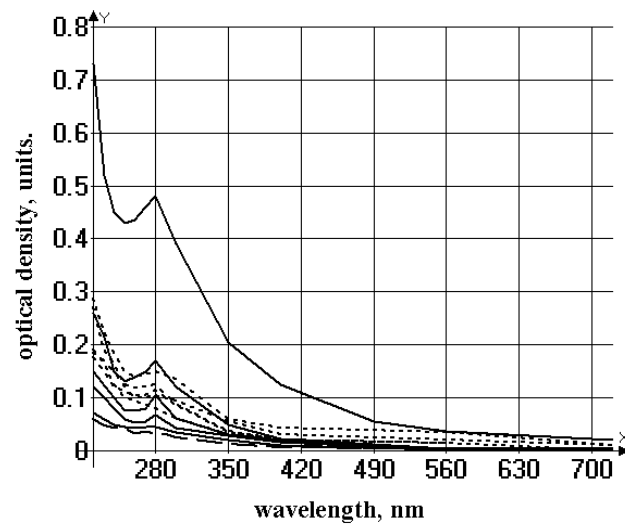

a

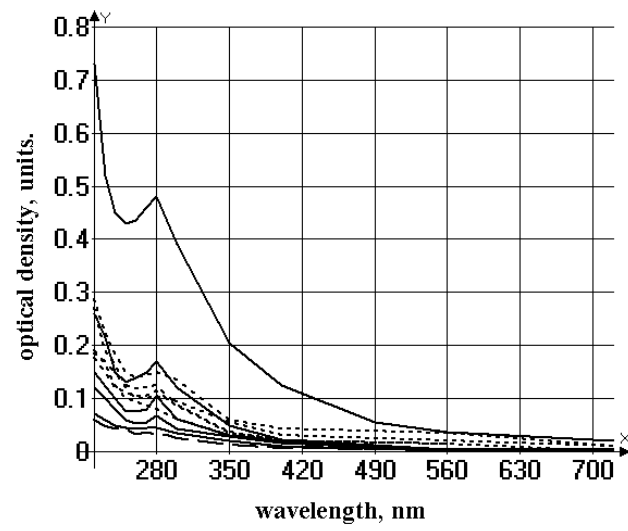

b

Fig. 1. Optical density of solutions of shallow (a) and large (b) fractions of crystals:

$\begin{array}{ll}\text { - } & \text { solutions of affination, } \\ \text { solutions after dissolution, } \\ \text { solution of pharmaceutical glucose }\end{array}$ 
Studies have shown that the thin fraction of crystals contains up to $44 \%$ of dyes that are concentrated in the outer film on the surface of the crystals, $56 \%$ of dyes fall into the crystal lattice, and in the fraction of large crystals, the specified ratio of coloring substances is distributed, respectively, by $30 \%$ and $70 \%$.

The figures show similar curves for all fractions of glucose affinity and dissolution, showing the same physical and chemical nature of the dyes in the volume of the crystal. The maximum peak at a wavelength of about $280 \mathrm{~nm}$, characteristic of 5-hydroxymethylfurfural, formed along with other dyes in the process of starch hydrolysis and giving color to the syrups, is allocated to all curves [8].

Distribution of colored impurities by depth of a crystal is presented in fig. $2 \mathrm{a}, \mathrm{b}$.
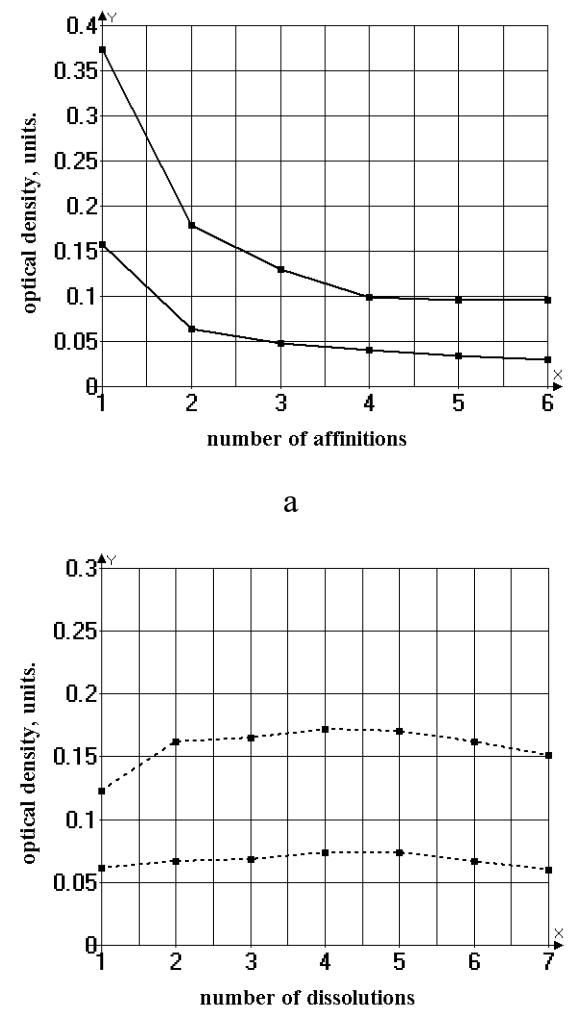

b

Fig. 2. An optical density of glucose solutions after serial affinations (a) and dissolutions (b) of crystals, at light filters of $220,400 \mathrm{~nm}$

From fig. 2a, extracted with affintions impurities characteristically, when all affinated reducing admixture is typical in the solutions with increasing number of washes of the crystals with saturated solution of glucose and becomes the minimum at the last, sixth affinitiy. The optical density of solutions for the fractions of solutions, characterizing the distribution of coloring substances inside the crystals, is shown in figure 2-b. By the nature of the curves revealed uneven distribution of impurities in the volume of crystals.
The optical density from the first to the fifth fractions of dissolution of crystals gradually increases, and for the last fractions from the fifth to the seventh decreases. Since the dissolution of crystals occurs from the periphery inward to the center, the uneven distribution of impurities in the volume of the crystal can be explained by the existing method of formation of crystallization centers, in which a third of the massecuit is used to form crystals for many cycles. In this case, some crystals as crystallization centers are in variable conditions, at different GE values of the intercrystalline solution, from which layer by layer on the surface of the crystal is adsorbed not only pure glucose, but also impurities of the depleted intercrystalline solution. In addition, basically, these crystals are conglomerates, fused from pieces of crystals. And, as you know, it is at the confluence of crystals (in the places of their contact) is the capture and accumulation of impurities. Impurities in the crystals fall as a result of occlusion and inclusion of crystallizing syrup. Sources of impurities in the syrup are water, starch impurities, hydrolysis conditions, used catalysts and adsorbents, evaporation methods, crystallization and centrifugation.

To improve the quality of glucose, work is being done to improve its technology. First of all, much attention is paid to the quality and conditions of starch conversion. The completeness of starch to glucose splitting, the corresponding level of impurities in the form of incomplete conversion products and reaction products accompanying hydrolysis, especially dyes, depends significantly on the quality of starch (protein content not more than $0.3 \%$ ) and its hydrolysis conditions (catalysts used and temperature).

Quality indicators syrups with different methods of starch hydrolysis are presented in table 4 .

TABLE IV. INDEXES OF SYRUPS QUALITY

\begin{tabular}{|c|c|c|c|}
\hline \multirow{2}{*}{ Contents, \% by DS } & \multicolumn{3}{|c|}{ Ways of receiving syrups } \\
\cline { 2 - 4 } & acid & acid-enzyme & enzymatic \\
\hline GE & $90-91$ & $94-95$ & $97-98$ \\
\hline & & & \\
glucose & 86 & 93 & $95-96$ \\
ashes & 1.6 & 0.4 & 0.2 \\
protein & 0.08 & 0.08 & 0.1 \\
oxymethylfur-furol & 0.3 & 0.008 & 0.003 \\
NaCl & 0.8 & 0.25 & - \\
& & & 0.3 \\
\hline chromacity, unit & 2.5 & 0.6 & \multirow{2}{*}{ optical density } \\
\hline
\end{tabular}

According to the data presented, it can be traced as the degree of starch hydrolysis, which is characterized by the glucose equivalent (GE) of the syrup, depends on the catalysts used.

During acid hydrolysis there are received syrups with GE of $90-91 \%$, low glucose content of $86 \%$, high content of products of incomplete conversion and a high chromacity of solutions. During the acid and enzymatic conversion, the use of acid at a liquefaction of starch and enzymes at the stage of a saccharification can considerably increase the syrup GE, furthermore respectively lower the impurity level in it and its chromacity. The deepest splitting of starch is reached with 
enzymes at both stages of conversion: $\alpha$-amylase at a liquefaction and glucoamylase at a saccharification stage. At the same time, the glucose content in syrups increases to 96$97 \%$, the level of impurities and the color of syrups decreases sharply [9]. The resulting hydrolysate is then filtered to separate suspended impurities in vacuum filters with filtering powders or through membranes with a pore diameter of $50 \mathrm{~nm}$ under pressure and clarified with activated carbon [10], evaporated under vacuum [11].

On cleaning of sugar syrups, active powdered coals of DCL brands, supplied to the Russian market by the English company Chemviron Carbon (Sutcliffe Speakman Ltd), have proven themselves well [12]. For the discoloration of sugar solutions, the author recommended coals of DCL brands with numbers $200,523,220,320$, for the discoloration of raw sugar solutions, DCL 200 and DCL 523 were the most effective.

\section{B. Tests of activated carbons for discoloration and purification of glucose syrups}

Coals for clarification of glucose syrups need to be selected carefully. For this purpose we analysed OU-B powdery active coals (Russia), CG-4 (Holland), Gn-A3 (Germany), Cx (France).The adsorption capacity, $\mathrm{pH}$ of an aqueous extract, content of water-soluble ashes were key factors for appreciation of their quality (tab. 5).

TABLE V. INDEXES OF COALS QUALITY

\begin{tabular}{|c|c|c|c|c|}
\hline \multirow{2}{*}{ Name of indexes } & \multicolumn{4}{|c|}{ Grades of activated carbon } \\
\cline { 2 - 5 } & $C G-4$ & $G n-A 3$ & $C x$ & $O U-B$ \\
\hline $\begin{array}{c}\text { Adsorption activity } \\
\text { by methylene blue, } \\
\text { mg/g }\end{array}$ & 332.5 & 332.0 & 366 & 220 \\
\hline $\begin{array}{c}\text { Adsorption activity } \\
\text { by molasses, \% }\end{array}$ & 108.22 & 107.5 & 113 & 77 \\
\hline $\begin{array}{c}\text { Common mass } \\
\text { fraction of ashes, \% }\end{array}$ & 4.50 & 4.86 & 4.32 & 7.8 \\
\hline Moisture, \% & 10.46 & 7.47 & 7.14 & 16.15 \\
\hline $\begin{array}{c}\text { PH of an aqueous } \\
\text { extract }\end{array}$ & 3.8 & 4.43 & 5.5 & 4.6 \\
\hline $\begin{array}{c}\text { Mass fraction of } \\
\text { water-soluble ashes, } \\
\%\end{array}$ & 0.4 & 0.01 & 0.25 & 1.0 \\
\hline
\end{tabular}

activity by molasses, methylene blue; $\mathrm{pH}$ within 3.8-5.5; the content of water-soluble ashes in them strongly varied from 0,01 to $1 \%$.

The coals were tested for the purification of syrups, the dosage had $1,3,5$ and $7 \%$ by weight of dry matter of the syrup. Discoloration was carried out at $70^{\circ} \mathrm{C}$ for 30 minutes when mixing coal with the product. The level of purification was controlled according to the syrup parameters: $\mathrm{pH}$, discoloration effect, specific rotation, as well as the content of solids, protein, ash and glucose in them. Studies have shown that for complete discoloration of the syrup and demineralization, the dosage of coal should be about $7 \%$ of the DS syrup.

Results of experiences are presented in tab. 6 .
TABLE VI. THE EFFICIENCY OF USING ACTIVATED CARBONS FOR PURIFICATION OF GLUCOSE SYRUPS

\begin{tabular}{|c|c|c|c|c|c|c|}
\hline \multirow{2}{*}{$\begin{array}{c}\text { Dosage of } \\
\text { coal, \% } \\
\text { by syrup } \\
\text { DS }\end{array}$} & \multirow{2}{*}{$\begin{array}{l}\text { Effect of } \\
\text { a deco- } \\
\text { loriza- } \\
\text { tion, \% }\end{array}$} & \multirow{2}{*}{$\mathbf{p H}$} & \multirow{2}{*}{$\begin{array}{c}\text { DS, } \\
\%\end{array}$} & \multicolumn{3}{|c|}{ Contents, \% by syrup DS } \\
\hline & & & & protein & ashes & glucose \\
\hline \multicolumn{2}{|c|}{ Initial syrup } & 5.1 & 34.2 & 0.31 & 0.26 & 95.8 \\
\hline \multicolumn{7}{|c|}{ Coal CG-4 (Holland) } \\
\hline 1 & 81.74 & 3.74 & 34.6 & - & - & - \\
\hline 3 & 90.43 & 3.33 & 34.2 & - & - & - \\
\hline 5 & 97.82 & 3.0 & 34.4 & 0.1 & 0.1 & 96.7 \\
\hline 7 & 100 & 2.7 & 34.3 & 0.06 & 0.04 & 97.6 \\
\hline \multicolumn{7}{|c|}{ Coal Gn-A3 (Germany) } \\
\hline 1 & 73.04 & 4.88 & 34.6 & - & - & - \\
\hline 3 & 95.65 & 4.83 & - & - & - & - \\
\hline 5 & 98.56 & 4.77 & 34.6 & 0.12 & 0.12 & 96.6 \\
\hline 7 & 100 & 4.56 & 33.6 & 0.08 & 0.06 & 97.3 \\
\hline \multicolumn{7}{|c|}{ Coal CX (France) } \\
\hline 7 & 100 & 5.03 & 34.2 & 0.07 & 0.06 & 97.5 \\
\hline \multicolumn{7}{|c|}{ Coal OU-B (Russia) } \\
\hline 7 & 98.96 & 5.5 & - & - & 0.3 & - \\
\hline
\end{tabular}

In experiments with the use of domestic coal OU-B for the purification of syrups, discoloration of them was satisfactory to $98 \%$ of the removed dyes, however, demineralization was not, on the contrary, the percentage of ash in the syrup increased by extracting minerals from coal. The best results on purification of syrups were received for GN-A3 coal containing the least amount of water-soluble mineral substances. When it was tested, we observed a high effective decolorization, the syrup $\mathrm{pH}$ did not change, the ash percentage in syrups decreased. The high purification performance of syrups from carbohydrate impurities is confirmed by decrease in specific rotation of glucose solutions from +56.60 to $+52.79^{\circ} \mathrm{C}$ (fig. 3 ).

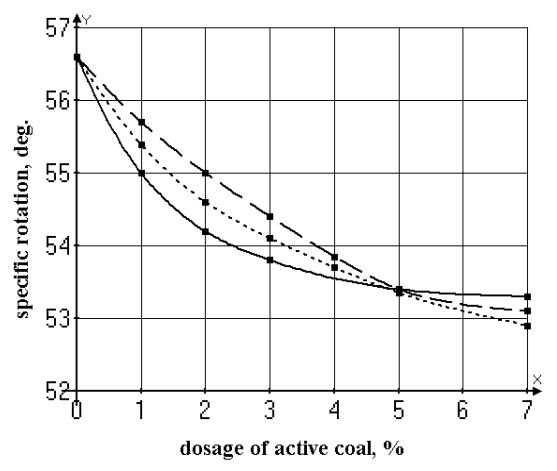

Fig. 3. Change of specific rotation of syrups during their decolorization by fissile coals:

$\begin{array}{ll} & \text { CG_4; } \\ -- & \text { GN-A3; } \\ -- & \text { CX }\end{array}$ 
The figure shows that the purity of syrups increases with increasing dosage of activated carbons for purification, which is confirmed by a decrease in the specific rotation of syrups. The lowest specific rotation of the syrup of $52.79^{\circ} \mathrm{C}$, close to the specific rotation of pure glucose, was obtained with coal GN-A3. Along with active coals, a high effect of purification of glucose syrups from impurities is achieved with ion exchange resins [13].

The quality of glucose also depends on the processes of crystallization and centrifugation. Depending on the purity of the syrups and temperature conditions of crystallization glucose is obtained in hydrate or anhydrous form. Hydrate glucose crystallizes at temperatures below $50{ }^{\circ} \mathrm{C}$ in anhydrous form at temperatures above $50{ }^{\circ} \mathrm{C}$. The hydrated molecule of glucose contains one molecule of crystallizing water and has a moisture content of $9 \%$, anhydrous glucose crystals have a moisture content of $0.5-1.0 \%$.

Conditions of crystallization of anhydrous and hydrated forms of glucose differ significantly, which also affects the quality of glucose.

\section{Crystallization of hydrated glucose}

The quality and yield of glucose crystals obtained at the stage of crystallization and centrifugation depend on the distribution of crystals by size and quality of the intercrystal solution. The main purpose of crystallization is to obtain crystals as large and uniform in size. The distribution of the size of glucose crystals is formed at the stage of grain formation and largely depends on the purity and degree of supersaturation of the syrup, the method of seed, the number of seed crystals and their size $[14,15]$. Low rate of crystallization, the imperfect method "run" of crystals, the temperature conditions of crystallization $\left(45-\right.$ of $\left.25^{\circ} \mathrm{C}\right)$, favorable for the growth of microorganisms, create conditions for reducing the quality of glucose and its microbial purity [16].

The acceleration of the "start-up" of crystals and the improvement of crystal homogeneity can be achieved by increasing the mixing rate [17]. Fine-grained glucose crystals used as a seed and moistened with one of the absolute aliphatic alcohols contribute to the improvement of the "starting" conditions of crystals, to the production of homogeneous crystals and to the increase of their purity [18]. Crystals, moistened with alcohol, as a surfactant are easily distributed with stirring in the syrup volume. This prevents adhesion, which is typical for thin crystals in the dry state, and also eliminates the dilution of syrup with depleted intercrystal solution when using massecuite for seed.

\section{Crystallization of anhydrous glucose}

The technology of producing anhydrous glucose involves the use of syrup obtained by enzymatic conversion. Anhydrous glucose crystallizes 5-6 times faster than hydrated glucose at high temperature $\left(55-75^{\circ} \mathrm{C}\right)$, which eliminates the cultivation of microflora, has the highest purity, almost sterile, and corresponds to the pharmaceutical standard. Crystallization is carried out by boiling massecuites in a vacuum apparatus at a temperature of $65-70^{\circ} \mathrm{C}$ or by lowering the temperature of the massecuites from 75 to $55^{\circ} \mathrm{C}$ in the crystallizer. The finished crystals grow large, are of the same size and shape, easily separated and washed from the intercrystal solution. Continuous crystallization in a vertical crystallizer [19] "Promotesto" improves distribution of sizes of uniform crystals. The crystallizer with a diameter of about 3 $\mathrm{m}$ has a height of $10-15 \mathrm{~m}$, is divided into sections with a coil surface of heat exchange. In the process of crystallization in it, as a seed, let us choose $1 / 3$ of the height of the upper part of the crystallizer and pumped into the upper part of the crystallizer to mix with the syrup. The heat exchange surface is on the coils located on sections, and the mixer design is more rational, minimizes formation of secondary crystals and provides their uniformity. Application for a priming of hydrated crystals, wetted with one of absolute aliphatic alcohols, is the original way for activation of nucleation rate, decreases in need for seed crystals and improvements of uniformity of crystals [18]. When interfusing with syrup, these crystals almost instantly collapse into the smallest particles (1$5 \mathrm{mkm}$ ), become crystallization centers and quickly begin to grow as anhydrous glucose. When using hydrated crystals moistened with alcohol, the necessary mass of seed crystals to provide the syrup with a full number of crystallization centers is reduced hundreds of times, the distribution of crystal sizes and, consequently, the conditions for separation and washing out of the intercrystal solution from their surface are improved.

\section{CONCLUSION}

In the article, the research of the content of painted impurity in glucose crystals and their migration over crystal volume sources and reasons of impurity inclusion in crystals is considered and measures for their decrease and elimination are proposed. The impurity level was determined by intensity of the chromacity of crystals solutions measured by their optical density. It is established that the optical density of solutions is higher for crystals of large fractions. A high chromacity of a large fraction of crystals can be explained with the fact that most of them consists of joined shallow crystals when while joining the painted intercrystal solution is included. At the same time, in crystals of the shallow fraction, up to $44 \%$ of colorants are concentrated on their surface and $56 \%$ of them are in crystals. In crystals of the large fraction, the ratio of impurity is distributed respectively as $30 \%$ and $70 \%$. The main sources of impurity accumulation in crystals are raw materials impurities such as starch, conditions of conversion, used catalysts, types of adsorbents and also technological modes of a crystallization, especially at the stage of "origination" of crystals. The use of enzymes for the conversion of starch, activated carbon and ion exchange resins that meet the requirements of glucose production contributes to the reduction of color and modernization of crystals. Activated carbon GN-A3 (Germany), used for discoloration and purification from mineral particles, was characterized by high efficiency. The use of activated carbons for discoloration in combination with ion exchange resins allows one to achieve higher technological and technical and economic indicators in the production of glucose. The used surfactants for making seed crystals promote acceleration of the nucleation rate of crystals, reducing the amount of seeds to improve crystal size 
distribution and glucose quality due to decreasing impurity level and microbial dissemination.

\section{References}

[1] L. S. Khvorova, "Production technology of pharmaceutical and food glucose", Food industry, 2008, no. 6, p. 56

[2] "International Society of Sports Nutrition position stand: Nutrient timing", Journal of the International Society of Sports Nutrition, 2008, no.5, p. 17, doi.org/10.1186/1550-2783-5-17

[3] . Xiaofeng Jiang, Chunying Zhu, Youguang Ma, "Density and viscosity of sorbitol/maltitol in L-ascorbic acid aqueous solutions at $\mathrm{T}=(293.15$ to 323.15) K", Journal of Molecular Liquids, 2013, vol. 188, pp. 67-73. https://doi.org/10.1016/j.molliq.2013.09.023 Getrights and content

[4] G. Pappenberger, H.-P. Hohmann, "Industrial Production of L-Ascorbic Acid (Vitamin C) and D-Isoascorbic Acid", Advances in biochemical engineering biotechnology, 2013, DOI:10.1007/10_2013_243.

[5] D. K Plamb, Pharmacological medicines in veterinary medicine, Moscow: Akvarium-Print, 2016, p. 1060

[6] M.M. Gubin, "Production of infusion solutions in Russia: features and prospects", Remedium, 2009, no. 3, pp. 55-59.

[7] State pharmacopeia of the USSR, 11th edition, Moscow: Medicine, 1989, vol. 1, p. 336; 1990, vol. 2, p. 400.

[8] A.R. Sapronov, R.A. Kolcheva, Colorants and their influence on quality of sugar, M.: Food industry, 1975, $349 \mathrm{p}$.

[9] M. P. Pinto, "Optimization of Processes for Production of Glucose Syrups and Dextrose Monohidrate", 2009, retrieved from https://fenix.tecnico.ulisboa.pt/downloadFile/395139430162/resumo.pdf
[10] P. Duflot, "Procede de fabrication d'un hydrolysat d'amidon a haute teneur en dextrose", Patent of France 9904177, 02.04.1999.

[11] V. Gnielinski, A. Mersman, F.Thurner, Verdampfung, Kristallisation,Trocknung, Springer-Verlag, 2013, p. 262

[12] L.A. Mitin, "Perfecting of technology of processing of raw sugar with application of adsorbents", The Abstract of the diss. of Cand.Tech.Sci. Mosk. state un-t of food ind. (MGUPP), Moscow, 2006, p. 22.

[13] M. R. Alessandrini, L. Ceccacci, H. Esber, "The Use of an lon Exchange Resin for Bone Demineralization", Journal of histotechnology, 1985, vol. 8(3), pp.151-153. DOI:0.1179/014788885794594698

[14] A. Markande, J. Fitzpatrick, A. Nezzal, L. Aerts, A. Redl, "Effect of initial dextrose concentration, seeding and cooling profile on the crystallization of dextrose monohydrate", Food and bioproducts processing, 2012, vol. 90, pp. 406-411.

[15] M. Parisi, M. Rivallin, A. Chianese, "Prediction of dextrose nucleation kinetics by the growth rate of crystallites", Chem. Eng. Technol., 2006, 29, no.2, pp. 265-270. DOI.10.1002/ceat 200500350

[16] T.A. Ladur, Z.M. Borodina, S.Ya. Grinchenko, A microflora and microbiological monitoring in starch syrup production, Moscow: tsniiteipishcheprom, 1981, no. 4, p. 24.

[17] M.L. Rasche, Mo Jing, R.D. Braatz, "Effect of jet velocity on crystal size distribution from antisolvent and cooling crystallizations in a dual impinging jet mixer", Chem.Eng.and Proc., 2015, pp. 242-247. DOI:10.1016/j.cep.2015.09.005.

[18] L.S. Khvorova, N.D. Lukin, L.V. Baranova, "Glucose Nucleation in the Presence of Surface Active Agents", Foods and Raw Materials, 2018 , vol. 6, no.1, pp. 62-69. DOI 10.21603/2308-4057-2017-2-62-69

[19] J.B. Leleu, "Process and apparatus for the preparation of anhydrous crystalline dextrose", European Patent EP0202999, 15.05.1985. 